\title{
The relationship of work-family conflict and quality of work life among female nurses in Medan
}

\section{Hubungan work-family conflict dengan quality of work life pada perawat perempuan di kota Medan}

\author{
Jesica Tania Sirait ${ }^{1}$, Yulinda Septiani Manurung*1, Winida Marpaung1 \\ ${ }^{1}$ Universitas Prima Indonesia, Medan, Indonesia
}

\begin{abstract}
This study examines the relationship between work-family conflict and the quality of work life among nurses in the city of Medan. The author hypothesized that higher level of work-family conflict would be associated with lower quality of work life. Participants were 105 female nurses from the city of Medan. We obtained the data using a questionnaire that measures work-family conflict and quality of work life. We analyzed the data using SPSS 17. The results showed a negative relationship between work-family conflict and quality of work life. Female nurses with higher work-family conflicts tended to have lower quality of work-life than those with lower work-family conflicts.
\end{abstract}

Keywords: work-family conflict, quality of work life, nurse

Abstrak. Studi ini meneliti hubungan antara work-family conflict dengan quality of work life. Dihipotesiskan bahwa peningkatan work-family conflict akan diikuti dengan penurunan quality of work life. Partisipan penelitian adalah 105 perawat berjenis kelamin perempuan di kota Medan. Data diperoleh melalui kuesioner yang mengukur work-family conflict dan quality of work life. Data dianalisis menggunakan SPSS 17. Hasil penelitian menunjukkan hubungan negatif antara work-family conflict dengan quality of work life. Perawat dengan work-family conflict yang tinggi cenderung memiliki quality of work life yang rendah.

Kata Kunci: work-family conflict, quality of work life, perawat

\section{Pendahuluan}

Kesehatan merupakan salah satu hal yang sangat penting bagi manusia. Di dalam kehidupan semua orang berharap menjadi orang yang sehat dan tidak mudah terkena penyakit. Banyak orang ingin menjadi sehat dengan menjalankan hidup sehat. Beberapa cara yang dapat dilakukan untuk berpola hidup sehat adalah istirahat yang cukup, berolahraga, mengatur pola makan, tidak merokok, tidak meminum-minuman keras dan lain sebagainya. Orang yang peduli dengan kesehatannya selalu menjaga pola hidup sehat seperti ini di dalam kehidupan sehari-harinya. Sayangnya, kebanyakan orang masih menganggap pola hidup sehat sebagai tidak berguna.

Pemerintah juga turut andil untuk menjaga dan merawat kesehatan masyarakatnya. Hal ini tertuang dalam Undang Undang Nomor 23 Tahun 1992 Tentang Kesehatan (Presiden Republik Indonesia, 1992). Kesehatan menurut Undang-undang ini adalah keadaan sejahtera dari badan, jiwa, dan sosial yang memungkinkan setiap orang hidup produktif secara sosial dan ekonomis. Salah

\footnotetext{
*Korespondensi: Yulinda Septiani Manurung, Universitas Prima, Jl. Sekip, Sei Putih Tim. I, Medan, Indonesia

Surel: yulindaseptianimanurung@unprimdn.ac.id
} 
satu bentuk nyata pemerintah dalam menjaga dan merawat kesehatan masyarakat adalah dengan menyediakan sarana kesehatan seperti Puskesmas, BPJS Kesehatan dan Askes (asuransi kesehatan). Menurut Undang Undang Nomor 44 Tahun 2009 Tentang Rumah Sakit (Presiden Republik Indonesia, 2009), Seseorang yang sedang tidak sehat akan dirawat di Rumah Sakit sebagai institusi yang berfungsi menyelenggarakan pelayanan pengobatan dan pemulihan kesehatan.

Perawat adalah salah satu sumber daya manusia terpenting di Rumah Sakit. Yang termasuk perawat menurut Undang-Undang Nomor 38 Tahun 2014 perawat adalah seseorang yang telah lulus pendidikan tinggi Keperawatan, baik di dalam maupun di luar negeri yang diakui oleh Pemerintah sesuai dengan ketentuan Peraturan Perundang-undangan (Presiden Republik Indonesia, 2014). Setiap perawat tentu saja ingin dapat melaksanakan tugas atau perannya dengan baik, namun tidak semua dapat berjalan secara optimal.

Korunka dan Hoonakker (2014) menjelaskan bahwa quality of work life menggambarkan pengalaman terkait pekerjaan yang lebih luas yang dimiliki seorang individu dalam pekerjaannya. Quality of work life melibatkan komponen positif (misal, kepuasan kerja, keterlibatan kerja, penggunaan keterampilan, kemungkinan pengembangan, masa depan yang berarti di tempat kerja, dan keseimbangan kerja-keluarga) tetapi juga komponen negatif (misal, kecemasan dan ketegangan dalam pekerjaan).

Tasdemir Afsar dan Burcu (2014) mengemukakan beberapa dimensi dari quality of work life. Yaitu, kebutuhan kesehatan dan keselamatan, kebutuhan ekonomi dan keluarga, kebutuhan sosial, kebutuhan harga diri, kebutuhan aktualisasi, kepuasan kebutuhan, dan kebutuhan estetika. Adapun faktor-faktor yang mempengaruhi quality of work life adalah kinerja, work-family conflict, iklim organisasi, kepuasan kerja, persepsi terhadap kinerja, komitmen karier, dan komitmen organisasi. Hasil penelitian Owolabi (2015) menunjukkan bahwa seseorang yang mengalami beban berlebihan atau menjalani peran secara ganda akan mengalami penurunan quality of work life. Ini menunjukkan bahwa quality of work life dapat dipengaruhi oleh work-family conflict.

Menurut Utaminingsih (2017), work-family conflict merupakan konflik yang terjadi secara simultan akibat tekanan dari dua atau lebih peran yang diharapkan. Bisa juga terjadi apabila pemenuhan satu peran bertentangan dengan peran lainnya. Menurut Greenhaus dan Beutell (1985), dimensi workfamily conflict adalah: time based conflict, strain based conflict, behavior based conflict. Penelitian ini dilakukan untuk mengetahui apakah ada hubungan antara work-family conflict dengan quality of work life pada perawat di kota Medan. Hal ini penting untuk ditelaah, mengingat kebanyakan perawat adalah perempuan, sebagai perempuan mereka harus dapat menyeimbangkan peran mereka sebagai istri di rumah dan peran mereka sebagai perawat di rumah sakit.

\section{Metode}

Penelitian ini dilakukan dengan pendekatan kuantitatif. Penelitian ini bertujuan untuk melihat keterkaitan antara dua variabel. Yaitu work-family conflict dan quality of work life.

\subsection{Partisipan}

Partisipan adalah 105 orang perawat berjenis kelamin perempuan yang bekerja di sebuah rumah sakit di kota Medan. Mereka telah bekerja setidaknya selama 2 tahun, sudah menikah, dan sudah memiliki anak. Partisipan direkrut secara insidental dan berpartisipasi secara sukarela. 


\subsection{Prosedur}

Setelah mendapatkan izin pelaksanaan penelitian di rumah sakit tempat para partisipan bekerja, sebanyak 150 kuesioner kami distribusikan di rumah sakit tempat para partisipan bekerja. Dari 150 kuesioner yang disebarkan, hanya 105 yang dapat diverifikasi lengkap untuk keperluan analisis.

\subsection{Alat ukur}

Penelitian ini melibatkan dua variabel yaitu, work-family-conflict sebagai variabel bebas dan quality of work life sebagai variabel terikat. Berikut ini adalah penjelasan mengenai definisi operasional, skoring, dan pengkategorian kedua variabel.

Quality of work life adalah pandangan anggota karyawan mengenai kenyamanan, keamanan kerja yang dirasakannya, serta persepsinya bahwa lingkungan kerjanya kondusif dan menyenangkan. Quality of work life ini diungkap dengan menggunakan skala yang disusun berdasarkan beberapa dimensi yaitu kebutuhan kesehatan dan keselamatan, kebutuhan ekonomi keluarga, kebutuhan sosial, kebutuhan harga diri, kebutuhan aktualisasi, kepuasan kebutuhan, kebutuhan estetika. Skala ini terdiri atas 32 aitem berskala 4 titik ( 1 = Sangat tidak sesuai $-4=$ Sangat sesuai $)$. Rentang minimum dan maksimumnya adalah $32 \times 1=32$ sampai $32 \times 4=128$, dengan mean hipotetiknya $\frac{32+128}{2}=80$ dan standar deviasi hipotetik $\frac{128-32}{6}=16$. Berdasarkan perhitungan ini, kategori skor quality of work life dapat dilihat di Tabel 1 (pada bagian Hasil).

Work-family conflict merupakan beban atau tekanan yang dialami seseorang akibat tuntutan peran ganda -sebagai pekerja dan peran sebagai anggota keluarga (misal, sebagai seorang ayah atau ibu dan sebagai seorang perawat di rumah sakit)- yang saling bertentangan. Work-family conflict diungkap dengan skala work-family conflict yang disusun berdasarkan dimensi work-family conflict yaitu time based conflict, strain based conflict, behavior based conflict. Skala work-family conflict terdiri atas 29 aitem dengan pilihan jawaban skala 4 titik ( 1 = Sangat tidak sesuai $-4=$ Sangat sesuai $)$. Rentang maksimum dan minimumnya adalah $29 \times 1=29$ sampai $29 \times 4=116$, dengan mean hipotetiknya $\frac{29+116}{2}=72.5$. Standard deviasi hipotetik dalam penelitian ini adalah $\frac{116-29}{6}=14.5$. Berdasarkan perhitungan ini, kategori skor work-family conflict dapat dilihat di Tabel 2 (pada bagian Hasil).

\section{Hasil}

Dari skala quality of work life yang diisi partisipan, diperoleh mean empirik sebesar 94.03 dengan standar deviasi 11.94. Kategorisasi partisipan pada variabel quality of work life dapat dilihat pada Tabel 1. Dapat dilihat pada Tabel 1, tidak satu orang pun partisipan yang memiliki quality of work life rendah, partisipan memiliki skor quality of work life antara sedang dan tinggi.Dari skala work-family conflict yang diisi partisipan, diperoleh mean empirik sebesar 64.47 dengan standard deviasi 9.66. Kategorisasi work-family conflict dapat dilihat pada Tabel 2. Dapat dilihat pada Tabel 2, kampur seperempat partisipan melaporkan work-family conflict pada kategori rendah. Pada umumnya, partisipan memiliki work-family conflict pada taraf sedang. Hanya sebagian kecil partisipan yang memiliki work-family conflict pada kategori tinggi. 
Tabel 1: Kategorisasi quality of work life partisipan

\begin{tabular}{llll}
\hline Rentang nilai & Kategori & Jumlah $(N)$ & Persentase $(\%)$ \\
\hline$x<66$ & Rendah & 0 & 0 \\
$65<x<96$ & Sedang & 59 & 56.19 \\
$x>95$ & Tinggi & 46 & 43.81 \\
\hline
\end{tabular}

Tabel 2: Kategorisasi work-family conflict partisipan

\begin{tabular}{llll}
\hline Rentang nilai & Kategori & Jumlah $(N)$ & Persentase $(\%)$ \\
\hline$x<58$ & Rendah & 24 & 22.85 \\
$58<x<88$ & Sedang & 59 & 75.23 \\
$x>87$ & Tinggi & 2 & 1.9 \\
\hline
\end{tabular}

\subsection{Uji asumsi}

Uji normalitas dilakukan agar dapat mengetahui apakah setiap variabel penelitian telah menyebar secara normal atau tidak. Uji normalitas sebaran menggunakan uji Kolmogorov-Smirnov test. Data dikatakan berdistribusi normal jika $p>.050$ (Field, 2009). Hasil menunjukkan baik quality of work life $(Z=0.67, p=.382)$ dan work-family conflict $(Z=0.53, p=.470)$ menyebar dengan normal.

Uji linearitas digunakan untuk mengetahui apakah distribusi data penelitian yaitu variabel quality of work-life dan work-family conflict memiliki hubungan linear. Variabel quality of work life dan work-family conflict dikatakan memiliki hubungan linear jika nilai $p<.050$. Uji linearitas antara work-family conflict dan quality of work-life bersifat linear, $F=51.66, p<.001$.

\subsection{Korelasi antara work-family conflict dengan quality of work-life}

Setelah uji asumsi diterima, selanjutnya dilakukan uji hipotesis. Hipotesis dalam penelitian ini adalah hubungan negatif antara quality of work-life dengan work-family conflict. Berdasarkan tujuan penelitian dilakukan uji pearson correlation.

Berdasarkan hasil analisis korelasi antara quality of work-life dengan work-family conflict, diperoleh koefisien korelasi product moment $r=-.54, p<0.001$. Hal ini menunjukkan adanya korelasi negatif antara quality of work-life dan work-family conflict. Sesuai dengan hipotesis yang diajukan, semakin tinggi tingkat work-family conflict, semakin tinggi rendah quality of work-life yang dimiliki para perawat.

\section{Diskusi}

Hasil penelitian ini menunjukkan bahwa terdapat hubungan negatif antara work-family conflict dengan quality of work life. Ini berarti bahwa semakin tinggi work-family conflict akan diikuti dengan semakin rendah quality of work life, begit pula sebaliknya. Dengan demikian, work-family conflict menjadi sebuah faktor yang penting untuk diperhatikan pada para perawat. Hal ini penting untuk dilakukan karena quality of work life yang baik biasanya berkorelasi positif dengan kualitas pekerjaan yang ditampilkan seseorang. Meskipun work-family conflict sebagian besar partisipan dapat dikategorikan pada taraf sedang, work-family conflict tetap perlu mendapatkan perhatian bagi pihak pengelola rumah sakit agar tidak sampai meningkat ke level yang tinggi. Berdasarkan penelitian ini, upaya mengontrol 
work-family conflict pada perawat dapat dilakukan dengan cara meningkatkan quality of work life. Selain itu, langkah-langkah lainnya yang dapat dilakukan adalah sebagai berikut.

Menurunkan work-family conflict dapat dilakukan dengan cara memberikan kesempatan kepada perawat membuat schedule kerja yang seimbang antara peran seseorang di dalam keluarganya dan perannya sebagai pekerja (Kelly, Moen, dan Tranby, 2011). Misalnya, manajemen rumah sakit dan para perawat dapat bersama-sama menciptakan schedule kerja yang mengakomodir kedua peran yang dimaksud. Penyesuaian antara schedule yang dibuat oleh perawat dan manajemen RS dapat memberikan sense of control pada para perawat, sehingga mereka dapat merasa lebih fleksibel dalam menjalankan peran-perannya. Selain itu, kesediaan manajemen rumah sakit untuk yang mampu mewadahi schedule yang fleksible sejatinya merupakan bentuk social support untuk para perawat. Suatu hal yang membuat para perawat merasa dihargai oleh manajemen. Hal-hal ini diharapkan dapat menurunkan work-family conflict di antara para perawat yang pada akhirnya dapat meningkatkan quality of work life para perawat.

Beberapa Kelemahan penelitian ini perlu disampaikan. Pertama, penelitian ini bersifat korelasional. Artinya hubungan sebab akibat antara work-family conflict dana quality of work life tidak dapat disimpulkan sepenuhnya, hanya dapat diasumsikan saja. Selain itu sampel pada penelitian ini hanya terbatas pada satu rumah sakit dan hanya melibatkan perawat perempuan. Hal ini membuat hubungan antara work-family conflict dan quality of work life pada laki-laki tidak dapat disimpulkan di dalam penelitian ini. Berdasarkan kelemahan ini, kami menyarankan penelitian selanjutnya dapat lebih ikut melibatkan perawat laki-laki. Selain itu, meskipun work-family conlict tidak mungkin dimanipulasi secara eksperimental, hubungan sebab akibat antara work-family conflct dan quality of work life dapat ditelaah dengan lebih meyakinkan melalui longitudinal studies (Ployhart dan Vandenberg, 2010).

Sebagai penutup, kami ingin menyimpulkan bahwa work-family conflict merupakan hal yang penting untuk diperhatikan perawat. Oleh karena itu, baik pihak manajemen rumah sakit dan perawat perlu menetapkan langkah-langkah untuk memitigasi kemungkinan work-family conflict di antara para perawat. Tentunya, tidak selamanya sebuah rumah sakit dapat mengakomodir kepentingan rumah tangga para perawat. Oleh karena itu, para perawat sendiri perlu mengembangkan schedule secara mandiri sehingga mereka dapat menyeimbangkan antara kehidupan mereka di dalam keluarga dan pekerjaan.

\section{Referensi}

Field, A. (2009). Discovering statistics using SPSS. Singapore: Sage.

Greenhaus, J. H., dan Beutell, N. J. (1985). Sources of conflict between work and family roles. Academy of Management Review, 10, 76-88. https://doi.org/10.5465/amr.1985.4277352

Kelly, E. L., Moen, P., dan Tranby, E. (2011). Changing workplaces to reduce work-family conflict: Schedule control in a white-collar organization. American Sociological Review, 76, 265-290. https://doi.org/10.1177/0003122411400056

Korunka, C., dan Hoonakker, P. (2014). The impact of ICT on quality of working life (C. Korunka dan P. Hoonakker, Eds.). https://doi.org/10.1007/978-94-017-8854-0

Owolabi, A. B. (2015). Effect of work-family conflict and job satisfaction on quality of work life. Advances in Social Sciences Research Journal, 2, 51-59. https://doi.org/10.14738/assrj.22.838 
Ployhart, R. E., dan Vandenberg, R. J. (2010). Longitudinal research: The theory, design, and analysis of change. Journal of Management, 36, 94-120. https://doi.org/10.1177/0149206309352110

Presiden Republik Indonesia. (1992). Undang Undang Republik Indonesia Nomor 23 Tahun 1992 Tentang Kesehatan. Jakarta: Lembaran Negara Republik Indonesia Nomor 100.

Presiden Republik Indonesia. (2009). Undang Undang Republik Indonesia Nomor 44 Tahun 2009 Tentang Rumah Sakit. Jakarta: Lembaran Negara Republik Indonesia Tahun 2009 Nomor 153.

Presiden Republik Indonesia. (2014). Undang Undang Republik Indonesia Nomor 38 Tahun 2014. Jakarta: Lembaran Negara Republik Indonesia Tahun 2014 Nomor 307.

Tasdemir Afsar, S., dan Burcu, E. (2014). The adaptation and validation of quality of work life scale to Turkish culture. Applied Research in Quality of Life, 9, 897-910. https://doi.org/10.1007/s114 82-013-9276-0

Utaminingsih, A. (2017). Gender dan wanita karir. Malang: Universitas Brawijaya Press. 